\title{
PRODUCTION OF CONSTRUCTION AGGREGATES FROM FLUE GAS DESULFURIZATION SLUDGE
}

\section{FINAL TECHNICAL REPORT}

August 18, 1998, through December 31, 1999

M. M. Wu, D. C. McCoy, R. O. Scandrol

M. L. Fenger, J. A. Withum, R. M. Statnick

May 2000

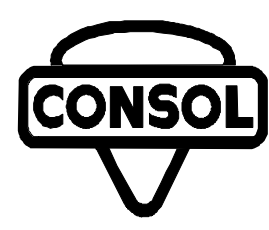

CONSOL Inc.

Research \& Development

4000 Brownsville Road

Library, PA 15129

412-854-6708

Under Contract to:

United States Department of Energy

Cooperative Agreement No. DE-FC26-98FT40027 


\section{DISCLAIMER}

This report was prepared as an account of work sponsored by an agency of the United States Government. Neither the United States Government nor any agency thereof, nor any of their employees, makes any warranty, express or implied, or assumes any legal liability or responsibility for the accuracy, completeness, or usefulness of any information, apparatus, product, or process disclosed, or represents that its use would not infringe private owned rights. Reference herein to any specific commercial product, process, or serve by trade name, trademark, manufacturer, or otherwise does not necessarily constitute or imply its endorsement, recommendation, or favoring by the United States Government or any agency thereof. The views and opinions of authors expressed herein do not necessarily state or reflect those of the United States Government or any agency thereof. 


\section{TABLE OF CONTENTS}

Page

EXECUTIVE SUMMARY

Background 1

Conclusions 2

Recommendations 2

PROJECT SUMMARY

Mix Design and Equipment Evaluation 4

Pilot Plant Design and Construction 4

Variations in FGD Sludge and Fly Ash During Pilot Plant Operations 5

Pilot Plant Operation and Aggregate Production $\quad 5$

$\begin{array}{ll}\text { Operating Problems and Solutions } & 7\end{array}$

Aggregate Product Evaluation $\quad 8$

REFERENCES

$\underline{\text { Table }}$

LIST OF TABLES

1 Solids Concentrations and Moisture Contents of FGD Sludge

Delivered on Different Dates 12

2 Analyses of Elrama Station FGD Sludge Delivered on Different Dates 12

3 Analyses of Fly Ash Samples from Allegheny Power Hatfield's Ferry

Station and Duquesne Light Cheswick Station 13

$4 \quad$ Plant Operations Summary 14

$5 \quad$ Manufactured Aggregate Pilot Plant On-Line Times 15

6 Properties of Manufactured Medium Weight Aggregates Produced at the Pilot Plant from 5/27/99 to 6/2/99 16

7 Properties of Manufactured Lightweight Aggregates Produced at the Pilot Plant from 6/5/99 to 6/11/99

8 Properties of Manufactured Road Aggregate 1 Produced at the Pilot Plant from 6/14/99 to 6/21/99

9 Properties of Manufactured Road Aggregate 2 Produced at the Pilot Plant from 6/23/99 to 6/30/99

10 Properties of Manufactured Road Aggregate 2R Produced at the Pilot Plant from 9/9/99 to 9/15/99

\section{LIST OF FIGURES}

Figure

Page

1 CONSOL Manufactured Aggregate Process Flow Scheme (Simplified) 19

2 A Photograph of the Pilot Plant During Construction 20

3 Manufactured Aggregates in Stockpile 21

$4 \quad$ FGD Sludge to Mixer Rate 22

5 Fly Ash to Mixer Rate 22

LIST OF FIGURES (Continued) 
Figure

Page

$6 \quad$ Other Components to Mixer Rate

23

7 Green Aggregate Production Rate

23

8 On-Stream Operating Factor

24

\section{LIST OF APPENDICES}

Appendix

Page

A1 Operations History

A1-1 


\section{EXECUTIVE SUMMARY}

\section{BACKGROUND}

Through a cooperative agreement with DOE, the Research and Development Department of CONSOL Inc. (CONSOL R\&D) teamed with SynAggs, Inc. and Duquesne Light to design, construct, and operate a $500 \mathrm{lb} / \mathrm{h}$ continuous pilot plant to produce manufactured aggregates from a mixture of lime wet flue gas desulfurization (FGD) sludge, fly ash, and other components. The pilot plant was designed to provide process scale-up data and information concerning continuous operations based on the bench-scale aggregate production unit. Over the last ten years, CONSOL R\&D developed a disk pelletization process to produce manufactured aggregates from coal combustion by-produces at the bench-scale. ${ }^{1}$ The aggregates were made using a three-step process that includes mixing, pelletizing, and curing. A variety of useful products, such as lightweight aggregates, American Association of State Highway and Transportation Officials (AASHTO) Class A aggregates, and concrete aggregates, were produced in a semi-continuous bench-scale unit. Typically, 200 to $400 \mathrm{lb}$ of aggregate was produced in a bench-scale run. Small field demonstrations using $1200 \mathrm{lb}$ to $5000 \mathrm{lb}$ of manufactured aggregates made in the semi-continuous bench-scale production were conducted. ${ }^{2}$ Aggregates produced from fluidized-bed combustion (FBC) ash and lime wet FGD sludge were used in road construction demonstrations. Aggregates made from spray dryer absorption (SDA) ash and lime wet FGD sludge were used to manufacture concrete masonry units. The aggregate production and development program was successful at bench-scale; however, continuous operation of the process had not been demonstrated. The greatest technological uncertainty was the ability to operate the process in a fully-integrated, continuous manner, and to evaluate scale-up parameters. To evaluate continuous operations and scaleup parameters, the process must be tested and demonstrated at the pilot scale. A proposal to build and operate a continuous aggregate production pilot plant was submitted to DOE in November 1997. The cooperative agreement was awarded by DOE in May 1998.

The objectives of the agreement were to: 1) demonstrate continuous, fully-integrated, longterm operation of the CONSOL manufactured aggregate process to produce aggregate from FGD sludge; 2) produce large quantities of specification aggregates for subsequent demonstrations; 3 ) develop operating data to design and cost a commercial plant. The mix design used for aggregate production was formulated during bench-scale tests and used to design the $500 \mathrm{lb} / \mathrm{h}$ pilot plant. The design and fabrication of the curing vessel was conducted specifically for the pilot plant. The pilot plant design was completed in December 1998, and construction was completed in April 1999. All major equipment for the pilot plant, except the curing vessel, was ordered. The pilot plant operation started on May 18, 1999. The aggregates were produced from May 25 to July 1, 1999. Lime wet FGD sludge from Duquesne Light Elrama Station and fly ash from either Allegheny Power Hatfield's Ferry Station or Duquesne Light Cheswick Station were used during the pilot plant tests. More than 130 tons of specification aggregates, including lightweight aggregate, medium-weight aggregate, and road aggregate were produced with different mix formulations. Additional off-specification material was produced during pilot plant start-up and during transition periods between different aggregate products. Daily aggregate samples were collected for quality control and assurance. The aggregate quality evaluation was completed in August 1999. 


\section{CONCLUSIONS}

\section{Pilot Plant Operation}

1. The pilot plant successfully demonstrated the continuous, fully-integrated, long-term process operation, including the mixing, pelletizing, and curing steps for aggregate production. The curing vessel, which was designed for the pilot plant test, was operated in a mass flow mode and performed well during pilot plant operation.

2. The pilot plant test demonstrated process flexibility. The same equipment was used to produce lightweight, medium-weight, and road aggregates. The only change was the mix formulation. Aggregates were produced from a variety of mix designs and from FGD sludge with solids concentrations between $45.0 \%$ and $56.7 \%$ and moisture contents between $55.0 \%$ and $43.3 \%$.

3. The pilot plant provided operating data and experience to design and cost a commercial plant, which was not part of the cooperative agreement.

\section{Pilot Plant Aggregate Production}

1. Lightweight aggregate produced in the pilot plant meets ASTM C331 lightweight aggregate specifications for use in concrete masonry units.

2. Medium-weight aggregate produced in the pilot plant meets ASTM C33 concrete aggregate specifications for use in portland cement concrete and concrete block.

3. Road aggregate produced in the pilot plant meets AASHTO M283 Class A aggregate specifications for use in highway construction.

The pilot plant demonstration was a major step toward commercialization of the manufactured aggregate process to produce manufactured aggregates from coal combustion by-products. Although not required by the cooperative agreement, aggregates produced from pilot plant will be crushed to meet size specifications and used in field demonstrations. Crushed lightweight and medium-weight aggregates will be used to produce concrete masonry units in a commercial block plant. Crushed road aggregates will be used to construct a bituminous concrete pavement test patch for evaluation in actual service.

\section{RECOMMENDATIONS}

1. This project demonstrated that aggregates can be produced from lime wet FGD sludge and Class F fly ash. It is recommended to use the pilot plant to produce large qualities of aggregates from other sources (e.g., limestone wet FGD sludge, spray dryer ash and Class $\mathrm{C}$ fly ash) to demonstrate that the process can be used with other coal combustion by-products.

2. CONSOL and SynAggs, Inc., will conduct field demonstrations using the aggregates produced in the pilot plant. Utilization of coal combustion by-products is usually regulated by the state environmental agencies. It is recommended that additional pilot plant aggregates be produced from spray dryer, limestone FGD, and FBC 
material. The aggregates will be used in field demonstrations in different states (e.g., Ohio, Florida, and Texas) to gain product acceptance.

3. Economics for manufactured aggregate production depend on site-specific factors (e.g., feedstock and natural aggregate costs, landfill availability). It is recommended that commercial design and cost studies be conducted at selected utility sites to determine economic feasibility. 


\section{PROJECT SUMMARY}

\section{DESIGN AND EQUIPMENT EVALUATION}

Bench-scale semi-continuous tests were conducted to determine suitable mix design and process conditions for pilot plant operation. In semi-continuous operations, 200-400 lbs of aggregate were produced in each test for evaluation. The aggregate properties normally evaluated included LA abrasion index, soundness index, unit weight, grain size, and crush strength. The test results indicate that AASHTO Class A and lightweight aggregates can be produced from Duquesne Light Elrama Station centrifuged or filtered sludge, Allegheny Power Hatfield's Ferry Station or Duquesne Light Cheswick fly ash, and other components.

The optimum mix formulation and operating conditions at the bench-scale were used as a basis for the pilot plant heat and material balances and to size the pilot plant equipment. Where necessary, special tests were conducted to obtain information needed for equipment specification. FGD sludge pumping, dry feedstock solids, and pellet flow characteristics were conducted for equipment selection. Special solids flow and compaction tests were conducted by an equipment manufacturer for the design of the curing vessel, a key piece of equipment that must operate reliably without plugging. The tests were conducted on-site using fresh pellets prepared in the bench-scale unit. The results were used to design the curing vessel, which provided trouble-free operation.

\section{PILOT PLANT DESIGN AND CONSTRUCTION}

The pilot plant was designed to provide process scale-up data and information concerning fully integrated, continuous operation. Due to the proprietary nature of the process, only a simplified process flow scheme is shown in Figure 1. As indicated in Figure 1, the process steps include mixing feedstocks (FGD sludge, fly ash and other components) in a mixer, pelletizing the mixed products in a disk pelletizer, curing the pelletized products in a curing vessel and screening the cured aggregate.

Preliminary engineering design was initiated in April 1998 with the development of block diagram, flow sheets, P\&IDs and conceptual layouts. Equipment specifications and a bid package followed, with equipment procurement beginning in August 1998. Detailed engineering began with layouts of specific equipment as soon as the components were ordered.

Construction was begun in October 1998 with major runs of electric conduit, piping, and structural steel modifications. With the onset of winter, a delay in construction was encountered in January and February 1999. Construction resumed in March with the installation of the curing vessel. The pilot plant was ready for equipment calibration to begin in April 1999.

The aggregate pilot plant was constructed using an existing five-story steel support structure, which was modified to support additional load. Major equipment purchased commercially for the pilot plant included a mixer, a 36" i.d. disk pelletizer, a double-deck screen, two FGD sludge holding tanks, dust collection equipment, fly ash bins, two bucket elevators, a sludge mass flow meter, sludge metering pump, and pneumatic-operated diaphragm pumps. Other major equipment, including the fly ash silo, a bucket elevator, transfer screw conveyor, dry solids feeders, and hoppers, were provided by CONSOL R\&D. The existing equipment required 
some repair and modification. The curing vessel was fabricated on-site, based on the design developed during the bench-scale tests.

A photograph of the pilot plant after construction is shown in Figure 2. As indicated in the figure, the FGD sludge holding tanks, associated sludge transfer and pumping equipment, and the product screen are located at ground level. A disk pelletizer and the process control panel are located on the second floor. A mixer is located on the third floor. Solids feeders, hoppers, and associated solids handling equipment are located on the fourth and fifth floors. The pilot plant construction was completed in April 1999.

\section{VARIATIONS IN FGD SLUDGE AND FLY ASH DURING PILOT PLANT OPERATIONS}

FGD sludge delivered from Duquesne Light Elrama Station was used for aggregate production throughout pilot plant operation. Fly ash from Allegheny Power Hatfield's Ferry Station was used for medium-weight aggregate and road aggregate production. Fly ash from Duquesne Light Cheswick Station was used for lightweight aggregate production.

As shown in Table 1, FGD sludge delivered from April 27 to June 29, 1999, had a solids concentration between $45.0 \mathrm{wt} \%$ and $56.7 \mathrm{wt} \%$, and a moisture content between $55.0 \%$ and $43.3 \%$. Besides moisture content, ultimate and major element analyses of selected FGD sludge samples were conducted to determine the variation in FGD sludge compositions. The compositions of FGD sludge samples delivered at different times are listed in Table 2. Ultimate analyses show slight variations in carbon, hydrogen, nitrogen, sulfur, and ash contents. Major element analyses show some variations in $\mathrm{SiO}_{2}, \mathrm{Al}_{2} \mathrm{O}_{3}, \mathrm{Fe}_{2} \mathrm{O}_{3}, \mathrm{CaO}$, and $\mathrm{SO}_{3}$ contents. Carbon, hydrogen, and nitrogen contents are related to the amount of fly ash in the scrubber sludge. Sulfur content is related to the amount of sulfur removed in the FGD unit (i.e., $\mathrm{CaSO}_{3} \cdot 1 / 2 \mathrm{H}_{2} \mathrm{O}$ and $\mathrm{CaSO}_{4} \cdot 2 \mathrm{H}_{2} \mathrm{O}$ ) in the scrubber slurry. Ash contents (ultimate analyses) are related to the amount of fly ash components and sulfur-containing compounds. The fly ash components, represented by the total amount of $\mathrm{SiO}_{2}, \mathrm{Al}_{2} \mathrm{O}_{3}$, and $\mathrm{Fe}_{2} \mathrm{O}_{3}$, range from $24.32 \%$ to $33.89 \%$. The sulfur-containing components, represented by the total amounts of $\mathrm{CaO}$ and $\mathrm{SO}_{3}$, range from $57.15 \%$ to $71.68 \%$. Variations in moisture contents, fly ash components, and sulfur-containing compounds in FGD sludge are caused by the Elrama Station boiler and scrubber operating conditions. During the pilot plant operation, the mix design was continuously adjusted to accommodate the sludge composition variations. This demonstrated process flexibility for continuous aggregate production.

As shown in Table 3, fly ash from the Allegheny Power Hatfield's Ferry Station and Duquesne Light Cheswick Station have similar major element compositions, but differences in carbon and loss on ignition (LOI) concentrations. Cheswick Station fly ash has higher carbon concentration $(10.16 \%)$ and LOI (10.98\%) than the Hatfield's Ferry Station fly ash (6.29\% and $7.29 \%)$. Each fly ash has a total amount of $\mathrm{SiO}_{2}, \mathrm{Al}_{2} \mathrm{O}_{3}$, and $\mathrm{Fe}_{2} \mathrm{O}_{3}$ of about $83 \%$, indicating that both are Class $\mathrm{F}$ fly ash produced from bituminous coals. Aggregate production at the pilot plant was maintained in the transition between Cheswick and Hatfield's Ferry fly ashes, which demonstrated process flexibility in accommodating fly ash composition variations.

\section{PILOT PLANT OPERATION AND AGGREGATE PRODUCTION}

A simplified process flow scheme for the pilot plant is shown in Figure 1. Fly ash and FGD sludge are metered, along with other components, into a high intensity mixer. The mixer is 
essentially a hollow tube with a center rotating shaft, which is studded with mixing paddles. The paddles are screwed into the mixer shaft, which allows wall clearance and pitch to be adjusted. Depending on the pitch of the paddle, the material can be conveyed rapidly or held up in various zones along the length of the mixer. The shaft speed is variable, allowing mixing optimization. The well-mixed moist solids are discharged from the mixer onto a tilted disk pelletizer. On the disk, the moist solids roll up into round agglomerates or "green" pellets. By controlling the solids moisture content, the feed deposition location on the disk pelletizer, the disk rotating speed, and the disk angle, the pellet size and properties can be controlled. The green pellets continuously overflow the pelletizer and are transferred to the curing vessel where, at a relatively low curing temperature, the pellets cure into hard aggregates. The curing vessel is specially designed to provide solids mass flow without solids channeling or hangup. After curing, the solids are screened and the product is sent to storage.

Table 4 summarizes the manufactured aggregate pilot plant operations from December 1998 to July 15, 1999. A more detailed operation history is provided in Appendix A. Between January and April 1999, the pilot plant was under construction. During this period, the plant operations were confined to the operation of the equipment as it became available for testing. The work included checks of motor rotation for proper direction, checkout and calibration of pressure, level, and flow controls instrumentation, motor control sequencing logic checkout, and calibration of the solids feeders. A start-up manual was written and provided to the plant operators. By mid-April, the equipment checkout had progressed to the point at which the front half of the pilot plant (through pelletization) could be operated. Between mid-April and midMay, operators were trained, mixer operation was optimized, and mixer vibrating problems were corrected.

The mixer operation was optimized to obtain uniform blending between the various dry solids and between the dry solids and wet FGD sludge. Distinct inclusions within cured aggregates, which can be seen with the naked eye, indicate insufficient mixing. This can affect particle strength and other properties. Tests were run at various mixer speeds and combinations of mixer shaft paddle settings (i.e., number of paddle blades set to convey solids through the mixer versus those set to hold up or kick back solids). Not surprisingly, high shaft rotational speeds greatly reduced visual inclusions. Tests also were conducted to determine the best location of the sludge feed point into the mixer. A point near the mixer discharge was found to work best without over-agglomerating the mixed materials. Efforts were also made to minimize mixer vibration. The mixer speed, sludge feed point, paddle positions, and paddle design all affected vibration. Installation of tapered paddles greatly reduced mixer vibrations. However, the paddles wore rapidly in service. Later testing showed that un-tapered tungsten carbide tipped paddles had much longer life and were equally effective in reducing vibration.

On May 24, all the pilot plant equipment was on line and operating in a fully-integrated manner with cured product material being stockpiled. A photograph of the pilot plant following construction is shown in Figure 2. From May 24 onward, the pilot plant normally was operated 24 hours/day, 5 days/week. A photograph of stockpiled aggregate is shown in Figure 3 . Four products were made: lightweight aggregate (24.6 tons), medium-weight aggregate (11.8 tons), road aggregate made with additive $A 1$ (28.6 tons), and road aggregate made with additive A2 (42.9 tons). All tonnages are aggregate products. About 30 tons of start-up material, transition material, and off-spec materials also were produced during pilot plant operation. 
The feed rates of materials fed to the high intensity mixer are presented in Figures 4 through 7. Figure 7 is the green pellet production rate. In Figure 5, a distinction is made between logged rates and estimated rates for the fly ash fed to the mixer, because a feeder set point was substituted for the measured feed rate. This was done on several occasions due to problems with the feeder electronics. The feeder always delivered the appropriate quantity of material; however, if there was a power dip or if the feeder was electrically turned off, the output span for a communications channel to the data logger would reset to a default value. This did not affect the control with respect to the set point (which was based on other memory parameters that were not reset or affected during power losses or feeder shutdowns), but it resulted in an incorrectly-recorded feed rate. In general, the plots indicate that the pilot plant operations were usually stable and well-controlled. It is shown in Figure 7 that pilot plant operators were able to increase production as they gained experience. Early in the test program, the green aggregate production averaged less than $450 \mathrm{lb} / \mathrm{hr}(5 / 19 / 99-5 / 20 / 99)$. By 6/15/99, aggregate production was above $600 \mathrm{lb} / \mathrm{hr}$.

The pilot plant operating times and daily on-stream operating factors are listed in Table 5. Additionally, the on-stream operating factors that represent the fraction of the time the green pellets are fed to the curing vessel and not diverted to "slops" are shown graphically in Figure 8. The table and figure clearly show that the on-stream operating times improved with time increasing from an average of $28 \%$ for the first week of operation (5/18/99 to $5 / 20 / 99)$ to $97 \%$ during the last week of operation (6/28/99 to $7 / 1 / 99)$. The overall weighted average on-stream factor was $81 \%$. This increases to $86 \%$ if the results for the initial operations (first three days plotted in Figure 8) are neglected. During these initial operations, plant operators were debugging the integrated process operation. There were a number of unusual equipment problems some of which were caused by heavy rains.

The pilot plant start-up and shutdown times were not included in calculating the on-stream factors. This was done to better estimate the actual on-stream operating factor for seven day, round-the-clock operation that would be typical of a commercial plant. Under these conditions, start-up and shutdown times would become very small fractions of the annual operating hours. The pilot plant can be brought on-line from a cold start producing green pellets in as little as $45 \mathrm{~min}$. When the plant is shut down, typically four hours are needed to secure and cleanup the equipment.

After the tests were completed, the curing vessel was emptied to recover additional product material and to allow inspection. The inspection was conducted by lowering a borehole video camera into the vessel. The inspection showed that the curing vessel was in good condition with no evidence of erosion or corrosion of the metal surfaces. Only a small amount of agglomerated material (i.e., about $1 \%$ of the vessel inventory) was found adhering to the walls. The agglomerates were generally in shielded areas where it is likely that solids flow was low. The small amount of agglomerates found in the vessel are not an operational concern.

\section{OPERATING PROBLEMS AND SOLUTIONS}

Three main operating problem areas were identified: 1) mixer paddle blade wear, 2) metering pump wear, and 3) plugging at the solids transfer point after the pelletizer. In the high intensity mixer, paddle blades located upstream of the sludge injection point did not show wear. However, paddles located downstream of the sludge injection point could lose $3 / 8$ " to $1 / 2$ " of metal from the tips in a week. This occurred despite the use of paddles tipped with hard surface weld 
metal. During the testing, paddles were replaced when wear was deemed excessive. In subsequent tests following the DOE program, the problem was solved by using paddles with silver-soldered tungsten carbide tips.

A progressive cavity pump was used to meter the sludge flow to the high-intensity mixer. The stainless steel rotor of this pump did not appear to wear, but the rubber stator wore out on several occasions. This was noted by the need to operate the pump at higher and higher speeds to maintain the desired sludge rates. The sludge metering pump stator was replaced on $6 / 3 / 99,6 / 21 / 99$, and after the test program ended. The wear is likely due to the presence of abrasive fly ash in the FGD sludges used. For a commercial plant, this is not likely to be a major concern. Using a larger capacity pump operating at lower speeds with more stages to reduce the pressure drop per stage should solve the problem. Additionally, alternate stator materials could be used, or the feed system could be redesigned using rubber or urethane lined centrifugal pumps with flow control valves to meter the sludge.

The final area of concern is with the equipment at the transfer point just downstream of the pelletizer. This equipment would frequently plug during operations requiring a 15-20 minute shutdown to clear and clean. Redesign of the equipment is expected to correct the problems. Since this is a proprietary feature of the process, a further explanation can not be given here.

In summary, the pilot plant operating problems are not a major concern for a commercial installation. All problems are considered to be readily solvable with minimal equipment redesign. The pilot plant operating experience indicates that high on-stream operating factors (i.e., $+90 \%$ ) should be easily achievable for a commercial installation.

\section{AGGREGATE PRODUCT EVALUATION}

\section{ASTM and AASHTO Tests}

Aggregate products were collected daily from the product discharge belt for quality assurance and quality control. The properties of aggregates were determined to compare with aggregate specifications for use in construction, according to standard test procedures in ASTM or AASHTO. ASTM does not specify the diameter of sample holder used in soundness test (ASTM C88). A 4" i.d. sample holder, with the bottom made of 16 mesh screen, was used to determine sodium sulfate soundness index of manufactured aggregate.

Properties of manufactured medium weight aggregates produced from May 27 to June 2, 1999, are summarized in Table 6 and compared to the ASTM C-33 concrete aggregate specifications. As shown in Table 6, the aggregate produced at the pilot plant meet the coarse aggregate specifications for use in concrete construction. The manufactured aggregates also have a low average unit weight of $63.0 \mathrm{lb} / \mathrm{ft}^{3}$ and a high average crush strength of $267 \mathrm{lb}$. In comparison, commercial limestone and gravel aggregates have unit weight of about $100 \mathrm{lb} / \mathrm{tt}^{3}$ and crush strength of $200 \mathrm{lb}$ to $300 \mathrm{lb}$. Therefore, the manufactured medium-weight aggregates have an advantage of providing higher yield for concrete construction than commercial natural aggregates with comparable crush strength.

Properties of manufactured lightweight aggregates produced from June 5-11, 1999, are summarized in Table 7 and compared to the ASTM C-331 lightweight aggregate specifications. As shown in Table 7, the aggregates produced at the pilot plant meet the coarse lightweight aggregate specification for use in concrete masonry units. The aggregates also have an 
average crush strength of $137 \mathrm{lb}$, which is adequate for use in manufacturing concrete masonry block. $^{2}$

Properties of manufactured road aggregates produced from June 14-21, 1999, with additive A1 are summarized in Table 8 and compared to AASHTO M-283 Class A aggregate specifications. As shown in Table 8, the aggregates produced at the pilot plant meet the coarse Class A road aggregate specifications for use in highway construction. The manufactured road aggregates also have a low average unit weight of $61.7 \mathrm{lb} / \mathrm{ft}^{3}$ and a high average crush strength of $295 \mathrm{lb}$. As in the medium weight aggregate, the manufactured road aggregates can have better yield than commercial natural aggregates for road construction.

Properties of manufactured road aggregates produced from June 23-30, 1999, with additive A2 are summarized in Table 9 and compared to AASHTO M-283 Class A aggregate specifications. As shown in Table 9, the aggregates produced at the pilot plant meet the requirement in LA abrasion index and grain size but fail to meet the specification in soundness index. The high soundness indices are associated with the inclusions in aggregates. The inclusions were caused by mixer paddle blade wear toward the end of pilot plant operation (see the previous discussion in "Operating Problems and Solutions"). In a follow-up pilot plant test with modified paddle tips, additional road aggregates with additive A2 were produced again from September 9-15. CONSOL and SynAggs funded the test. As shown in Table 10, the aggregates from the repeat run meet all the requirements. The improved quality of the product from the repeat run illustrates the importance of adequate mixing to the final product quality. The manufactured road aggregates also have a low average unit weight of $60.6 \mathrm{lb} / \mathrm{ft}^{3}$ and a high average crush strength of $298 \mathrm{lb}$. The manufactured road aggregates can have better yield than commercial natural aggregates for road construction.

\section{PennDOT Tests}

Even though it was not included in the DOE program, a road demonstration was planned so that the durability of road aggregate under actual service conditions could be evaluated. Besides the ASTM soundness test method, a sodium sulfate soundness test was conducted for road construction demonstration in Pennsylvania, according to Pennsylvania Department of Transportation (PennDOT) test procedure. ${ }^{3}$ In the PennDOT soundness test, an aluminum sample pan was used as sample holder instead of a perforated sample holder (e. g., openwired or mesh sieve) as in ASTM procedures. In this study, the PennDOT test procedure was modified by using a Pyrex pan as a sample holder to avoid the reaction of aluminum with manufactured aggregate to form ettringite in sodium sulfate solution. High sodium sulfate soundness weight loss ranging from $24 \%$ to $86 \%$ were obtained with manufactured road aggregates. The high weight losses appeared to be associated with chemical attach of sodium sulfate solution on aggregate, not related to aggregate freeze/thaw characteristics. PennDOT Material Testing Laboratory conducted a freeze/thaw test $\left(-15^{\circ} \mathrm{F} / 70^{\circ} \mathrm{F}\right)$ with the alcohol-water only, in accordance to AASHTO T103 test procedure. ${ }^{4}$ Weight loss of less than $12 \%$ was obtained after 30 freeze/thaw cycles. In contrast, the sodium sulfate test uses five treatment cycles only. Without using sodium sulfate solution, the weight loss in AASHTO T103 is caused by freeze/thaw treatment only. Based on the AASHTO T103 freeze/thaw test results, PennDOT approved the highway construction demonstration for use of manufactured road aggregate in asphalt concrete. 


\section{Weathering Effect on Aggregate Properties}

Aggregates were collected from the outdoor piles five to ten weeks after the end of production. Outdoor exposure and aging had little effect on the aggregate properties. Aggregates had similar crush strength and LA abrasion index to those of aggregates collected directly from the pilot plant discharge belt. 


\section{REFERENCES}

1. Wu, M. M.; Winschel, R. A.; Hasenfus, G. J. "Production of Manufactured Aggregate from Coal Combustion By-Products", presented at the DOE Advanced Coal-Base Power and Environmental System'98 Conference, Morgantown, WV, July 1998.

2. Wu, M. M.; McCoy, D. C.; Fenger, M. L.; Scandrol, R. O.; Winschel, R. A.; Withum, J. A.; Statnick, R. M. "Production of Manufactured Aggregates from Flue Gas Desulfurization By-Products", presented at the 1999 International Ash Utilization Symposium, Lexington, KY, October 1999.

3. Pennsylvania Department of Transportation Test Method PTM 510, Soundness of Aggregate by use of Sodium Sulfate.

4. AASHTO Designation T-103, Standard Specification for Soundness of Aggregates by Freezing and Thawing. 
TABLE 1. SOLIDS CONCENTRATIONS AND MOISTURE CONTENTS OF FGD SLUDGE DELIVERED ON DIFFERENT DATES

\begin{tabular}{||c|c|c||}
\hline Delivered Date & Solids Concentration, wt \% & Moisture Content, wt \% \\
\hline $4-21-99$ & 56.7 & 43.3 \\
$5-27-99$ & 52.8 & 47.2 \\
$6-03-99$ & 47.7 & 52.3 \\
$6-07-99$ & 49.7 & 50.3 \\
$6-11-99$ & 51.0 & 49.0 \\
$6-14-99$ & 45.0 & 55.0 \\
$6-16-99$ & 48.1 & 51.9 \\
$6-18-99$ & 47.6 & 52.4 \\
$6-25-99$ & 56.7 & 43.3 \\
$6-29-99$ & 52.8 & 47.2 \\
\hline
\end{tabular}

TABLE 2. ANALYSES OF ELRAMA STATION FGD SLUDGE DELIVERED ON DIFFERENT DATES

\begin{tabular}{|c|c|c|c|c|c|}
\hline Sampling Date & $5 / 27$ & $6 / 11$ & $6 / 14$ & $6 / 16$ & $6 / 29$ \\
\hline $\begin{array}{l}\text { Moisture, wt \% (as rec.) } \\
\text { Ultimate Analysis, wt \% (dry) }\end{array}$ & 52.8 & 49.0 & 55.0 & 51.9 & 47.2 \\
\hline Carbon & 2.52 & 3.62 & 2.16 & 1.60 & 2.38 \\
\hline Hydrogen & 0.58 & 0.59 & 0.47 & 0.47 & 0.43 \\
\hline Nitrogen & 0.01 & 0.04 & 0.02 & 0.02 & $<0.01$ \\
\hline Sulfur & 14.07 & 12.50 & 14.72 & 15.80 & 14.68 \\
\hline Ash $\left(750^{\circ} \mathrm{F}\right)$ & 93.81 & 92.14 & 95.19 & 96.45 & 94.84 \\
\hline \multicolumn{6}{|l|}{ Major Element, wt \% (dry) } \\
\hline $\mathrm{SiO}_{2}$ & 16.24 & 20.24 & 15.11 & 14.37 & 16.01 \\
\hline $\mathrm{Al}_{2} \mathrm{O}_{3}$ & 7.77 & 9.71 & 7.31 & 7.02 & 8.07 \\
\hline $\mathrm{TiO}_{2}$ & 0.37 & 0.44 & 0.34 & 0.34 & 0.40 \\
\hline $\mathrm{Fe}_{2} \mathrm{O}_{3}$ & 3.38 & 3.94 & 3.08 & 2.93 & 3.26 \\
\hline $\mathrm{CaO}$ & 30.72 & 25.90 & 31.86 & 32.19 & 30.79 \\
\hline $\mathrm{MgO}$ & 1.24 & 1.13 & 1.00 & 1.11 & 1.00 \\
\hline $\mathrm{Na}_{2} \mathrm{O}$ & 0.23 & 0.23 & 0.18 & 0.18 & 0.17 \\
\hline $\mathrm{K}_{2} \mathrm{O}$ & 0.82 & 0.99 & 0.77 & 0.72 & 0.74 \\
\hline $\mathrm{P}_{2} \mathrm{O}_{5}$ & 0.15 & 0.21 & 0.15 & 0.16 & 0.13 \\
\hline $\mathrm{SO} 3$ & 35.18 & 31.25 & 36.80 & 39.49 & 36.70 \\
\hline $\mathrm{SiO}_{2}+\mathrm{Al}_{2} \mathrm{O}_{3}+\mathrm{Fe}_{2} \mathrm{O}_{3}$ & 27.39 & 33.89 & 25.50 & 24.32 & 27.34 \\
\hline $\mathrm{CaO}+\mathrm{SO}_{3}$ & 65.90 & 57.15 & 68.66 & 71.68 & 67.49 \\
\hline
\end{tabular}


TABLE 3 ANALYSES OF FLY ASH SAMPLES FROM ALLEGHENY POWER HATFIELD'S FERRY STATION AND DUQUESNE LIGHT CHESWICK STATION

\begin{tabular}{||l|r|r||}
\hline \hline & Hatfield's Ferry Station & Cheswick Station \\
\hline \hline Moisture, wt\% (as rec.) & 0.30 & 0.22 \\
Ultimate Analysis, wt \% (dry) & & \\
\hline Carbon & 6.29 & 10.16 \\
Hydrogen & 0.05 & 0.10 \\
Nitrogen & $<0.01$ & 0.03 \\
Sulfur & 0.50 & 0.42 \\
Ash $\left(750{ }^{\circ} \mathrm{F}\right)$ & 92.71 & 89.02 \\
Loss-on-Ignition & 7.29 & 10.98 \\
\hline $\mathrm{Major}$ Element, wt \% (dry) & & \\
$\mathrm{SiO}$ & & 46.34 \\
$\mathrm{Al}_{2} \mathrm{O}_{3}$ & 45.40 & 23.31 \\
$\mathrm{TiO}_{2}$ & 22.11 & 1.10 \\
$\mathrm{Fe}_{2} \mathrm{O}_{3}$ & 1.05 & 13.19 \\
$\mathrm{CaO}$ & 15.46 & 2.60 \\
$\mathrm{MgO}$ & 5.48 & 0.79 \\
$\mathrm{Na}_{2} \mathrm{O}$ & 0.94 & 0.55 \\
$\mathrm{~K}_{2} \mathrm{O}$ & 0.78 & 1.63 \\
$\mathrm{P}_{2} \mathrm{O}_{5}$ & 1.44 & 0.30 \\
$\mathrm{SO}_{3}$ & 0.41 & 0.92 \\
$\mathrm{SiO}_{2}+\mathrm{Al}_{2} \mathrm{O}_{3}+\mathrm{Fe}_{2} \mathrm{O}_{3}$ & 1.26 & 82.84 \\
\hline \hline
\end{tabular}




\section{TABLE 4. PLANT OPERATIONS SUMMARY}

$12 / 28 / 98$

$1 / 22 / 99$

2/23/99

$3 / 31 / 99$

$4 / 8 / 99$

$4 / 15 / 99$

$4 / 15 / 99-5 / 14 / 99$

$5 / 17 / 99$

$5 / 24 / 99$

$5 / 17 / 99-5 / 29 / 99$

$6 / 1 / 99-6 / 10 / 99$

6/11/99 - 6/22/99

6/23/99 - 7/1/99

$7 / 15 / 99$
Received first truck delivery of fly ash.

Began equipment check out. During the month, the installation of the pelletizer was completed; equipment rotation direction was checked for the conveyors, the solids feeders, mixer, and the pelletizer. Control logic was developed for the programmable logic controller (PLC) and bench tested for proper motor sequencing.

Began preliminary operator training. During the month, the curing vessel was installed and the sludge pump was relocated to eliminate, as much as possible, air bubbles in the sludge fed to the flow meter. Heat tracing details were finalized for the curing vessel and the bucket elevator that conveys green aggregate to the curing vessel.

Received the first load of FGD sludge. During March, major plant construction was completed, except for the installation of five connecting solids transfer chutes. The curing vessel/bucket elevator heat tracing temperature controller malfunctioned and was sent to the manufacture for servicing.

Issued start-up manual to operators.

Operated the front half of the pilot plant through the pelletization step.

Optimized mixer operation and conducted operator training.

Began feeding green pellets to the curing vessel.

Initiated full integrated process operation with product material (mediumweight aggregate) going to stockpile.

Medium-weight aggregate production period with additive A1 at level 1 .

Lightweight aggregate production period.

Road aggregate production period with additive $\mathrm{A} 1$ at level 2 .

Road aggregate production period with additive A2.

Conducted curing vessel inspection. 
TABLE 5. MANUFACTURED AGGREGATE PILOT PLANT ON-LINE TIMES

\begin{tabular}{|c|c|c|c|}
\hline Date & $\begin{array}{l}\text { Operating } \\
\text { Time, hrs }\end{array}$ & $\begin{array}{l}\text { Diversion } \\
\text { Time, hrs }\end{array}$ & $\begin{array}{c}\text { Percent of Time } \\
\text { On-Line }\end{array}$ \\
\hline $05 / 17$ & No Data & -- & $\overline{--}$ \\
\hline $05 / 18$ & 14.40 & 11.12 & 23 \\
\hline $05 / 19$ & 24.00 & 16.75 & 30 \\
\hline $05 / 20$ & 12.50 & 8.50 & 32 \\
\hline $05 / 21$ & No Data & & \\
\hline \multicolumn{4}{|l|}{$05 / 22$} \\
\hline \multicolumn{4}{|l|}{$05 / 23$} \\
\hline $05 / 24$ & No Data & -- & -- \\
\hline $05 / 25$ & 18.78 & 5.25 & 72 \\
\hline $05 / 26$ & 24.00 & 5.75 & 76 \\
\hline $05 / 27$ & 24.00 & 4.25 & 82 \\
\hline $05 / 28$ & 20.00 & 2.00 & 90 \\
\hline \multicolumn{4}{|l|}{$05 / 29$} \\
\hline \multicolumn{4}{|l|}{$05 / 30$} \\
\hline $05 / 31$ & Holiday & & \\
\hline $06 / 01$ & 4.50 & 2.25 & 50 \\
\hline $06 / 02$ & 24.00 & 3.50 & 85 \\
\hline $06 / 03$ & 24.00 & 12.00 & 50 \\
\hline $06 / 04$ & 24.00 & 3.25 & 86 \\
\hline $06 / 05$ & 20.00 & 4.50 & 78 \\
\hline \multicolumn{4}{|l|}{$06 / 06$} \\
\hline $06 / 07$ & 23.25 & 1.25 & 95 \\
\hline $06 / 08$ & 24.00 & 1.50 & 94 \\
\hline $06 / 09$ & 24.00 & 0.75 & 97 \\
\hline $06 / 10$ & 24.00 & 3.25 & 86 \\
\hline $06 / 11$ & 20.00 & 3.25 & 84 \\
\hline \multicolumn{4}{|l|}{$06 / 12$} \\
\hline \multicolumn{4}{|l|}{$06 / 13$} \\
\hline $06 / 14$ & 23.00 & 0.75 & 97 \\
\hline $06 / 15$ & 24.00 & 8.75 & 64 \\
\hline $06 / 16$ & 24.00 & 2.25 & 91 \\
\hline $06 / 17$ & 24.00 & 3.75 & 84 \\
\hline $06 / 18$ & 10.00 & 1.25 & 88 \\
\hline \multicolumn{4}{|l|}{$06 / 19$} \\
\hline \multicolumn{4}{|l|}{$06 / 20$} \\
\hline $06 / 21$ & 11.00 & 0.50 & 95 \\
\hline $06 / 22$ & 24.00 & 3.25 & 86 \\
\hline $06 / 23$ & 24.00 & 0.50 & 98 \\
\hline $06 / 24$ & 24.00 & 1.50 & 94 \\
\hline $06 / 25$ & 24.00 & 7.50 & 69 \\
\hline \multicolumn{4}{|l|}{$06 / 26$} \\
\hline \multicolumn{4}{|l|}{$06 / 27$} \\
\hline $06 / 28$ & 22.50 & 0.75 & 97 \\
\hline $06 / 29$ & 24.00 & 0.25 & 99 \\
\hline $06 / 30$ & 24.00 & 0.75 & 97 \\
\hline $07 / 01$ & 12.75 & 0.50 & 96 \\
\hline Total & 644.68 & 121.37 & \\
\hline \multicolumn{4}{|c|}{$\begin{array}{l}\text { Weighted On-Stream } \\
\text { Factor }\end{array}$} \\
\hline
\end{tabular}


TABLE 6. PROPERTIES OF MANUFACTURED MEDIUM WEIGHT AGGREGATES PRODUCED AT THE PILOT PLANT FROM 5/27/99 TO 6/2/99

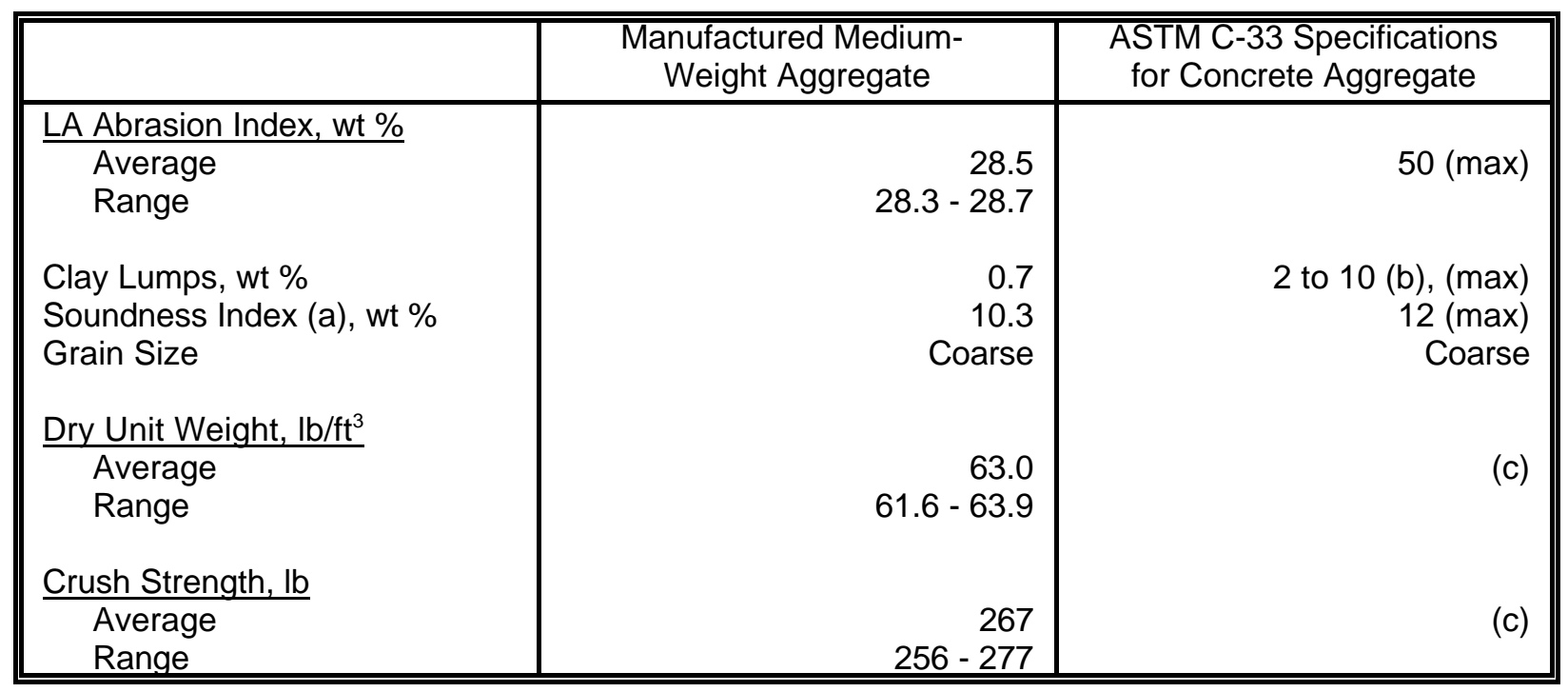

(a) Determined in accordance with ASTM (or AASHTO) procedure

(b) Depends on application

(c) No Specification

TABLE 7. PROPERTIES OF MANUFACTURED LIGHTWEIGHT AGGREGATES PRODUCED AT THE PILOT PLANT FROM 6/5/99 TO 6/11/99

\begin{tabular}{|c|c|c|}
\hline & $\begin{array}{c}\text { Manufactured Lightweight } \\
\text { Aggregate }\end{array}$ & $\begin{array}{c}\text { ASTM C-331 Specifications for } \\
\text { Lightweight Aggregate }\end{array}$ \\
\hline $\begin{array}{l}\text { Dry Unit Weight, lb/ } \mathrm{ft}^{3} \\
\text { Average } \\
\text { Range }\end{array}$ & $\begin{array}{r}49.0 \\
47.9-52.7\end{array}$ & 55 (max) \\
\hline \begin{tabular}{l} 
Clay Lumps, wt \% \\
\multicolumn{1}{c}{ Average } \\
Range \\
Organic Impurity \\
Staining \\
Grain Size \\
Crush Strength, lb \\
\multicolumn{1}{c}{ Average } \\
Range
\end{tabular} & $\begin{array}{r}1.7 \\
1.65-1.75 \\
\text { Negative } \\
\text { Negative } \\
\text { Coarse } \\
\\
137 \\
121-146\end{array}$ & $\begin{array}{r}2 \text { (max) } \\
\text { Negative } \\
\text { Negative } \\
\text { Coarse }\end{array}$ \\
\hline
\end{tabular}


TABLE 8. PROPERTIES OF MANUFACTURED ROAD AGGREGATE 1 PRODUCED AT THE PILOT PLANT FROM 6/14/99 to 6/21/99

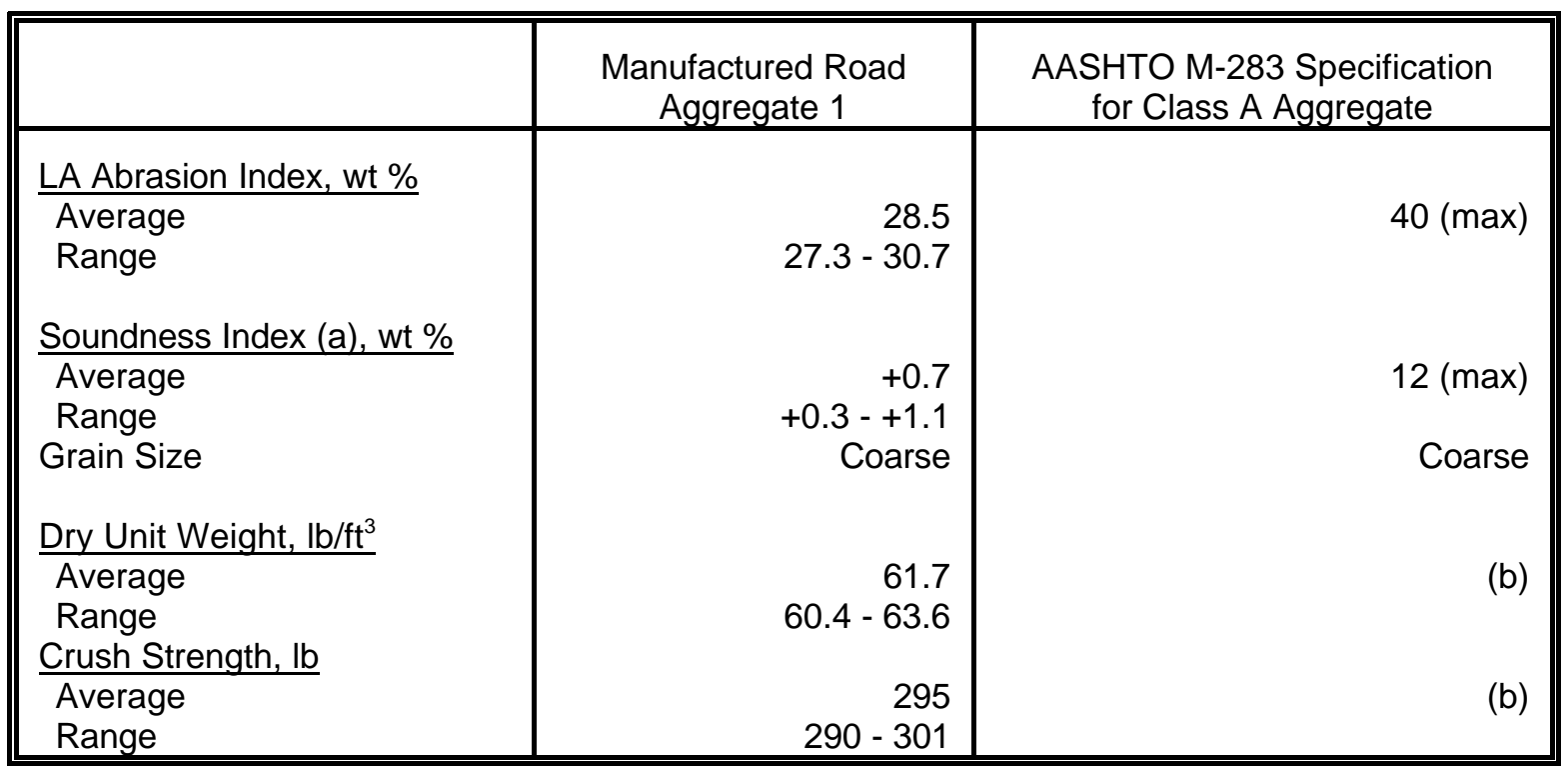

(a) Determined in accordance with ASTM (or AASHTO) procedure. + represents weight gain

(b) No Specification

TABLE 9. PROPERTIES OF MANUFACTURED ROAD AGGREGATE 2 PRODUCED AT THE PILOT PLANT FROM 6/23/99 to 6/30/99

\begin{tabular}{||l|r|r||}
\hline & $\begin{array}{r}\text { Manufactured Road } \\
\text { Aggregate 2 }\end{array}$ & $\begin{array}{c}\text { AASHTO M-283 Specification } \\
\text { for Class A Aggregate }\end{array}$ \\
\hline $\begin{array}{l}\text { LA Abrasion Index, wt\% } \\
\text { Average }\end{array}$ & 30.2 & 40 (max) \\
Range & $28.2-30.1$ & \\
Soundness Index (a), wt\% & 24 & 12 (max) \\
\hline Average & $16.6-31.7$ & Coarse \\
Range & Coarse & \\
Grain Size & & (b) \\
Dry Unit Weight, lb/ft ${ }^{3}$ & 60.6 & \\
Average & $57.2-61.9$ & (b) \\
Range & & 298 \\
Crush Strength, lb & $252-350$ & \\
Average & & \\
Range & & \\
\hline
\end{tabular}

(a) Determined in accordance with ASTM (or AASHTO) procedure

(b) No Specification 
TABLE 10. PROPERTIES OF MANUFACTURED ROAD AGGREGATE 2R PRODUCED AT THE PILOT PLANT FROM 9/09/99 to 9/15/99

\begin{tabular}{||l|r|r||}
\hline & $\begin{array}{r}\text { Manufactured Road } \\
\text { Aggregate 2R }\end{array}$ & $\begin{array}{c}\text { AASHTO M-283 Specification } \\
\text { for Class A Aggregate }\end{array}$ \\
\hline $\begin{array}{l}\text { LA Abrasion Index, wt \% } \\
\text { Average }\end{array}$ & 25.9 & 40 (max) \\
Range & $25.8-26.1$ & \\
Soundness Index (a), wt \% & 5.6 & 12 (max) \\
\hline Average & $1.8-10.2$ & Coarse \\
Range & Coarse & \\
Grain Size & & (b) \\
Dry Unit Weight, lb/ft ${ }^{3}$ & $63.1-65.5$ & \\
\hline Average & & (b) \\
Range & 349 & \\
Crush Strength, lb & 376 & \\
\hline Average & & \\
Range & & \\
\hline
\end{tabular}

(a) Determined in accordance with ASTM (or AASHTO) procedure

(b) No Specification 


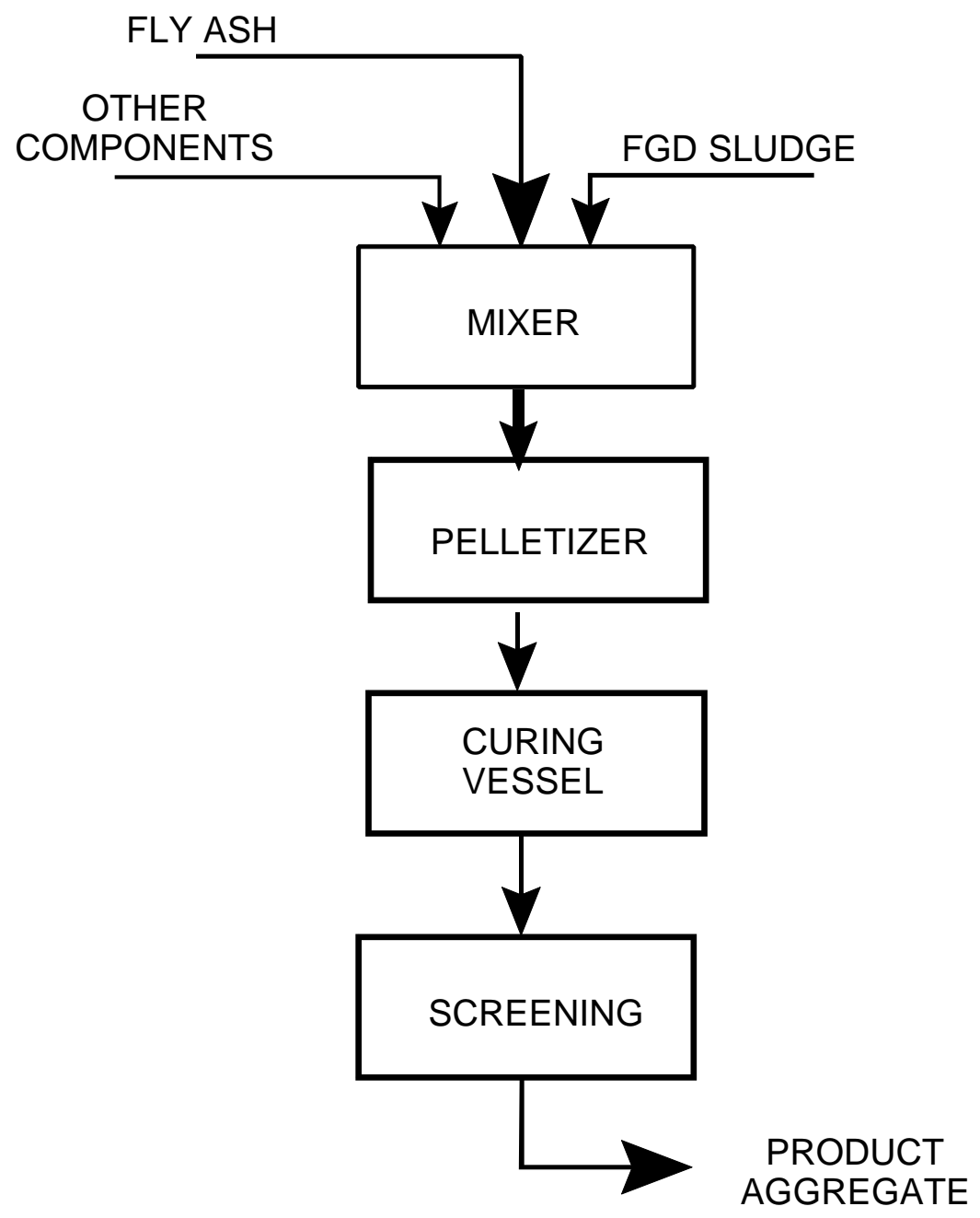

Figure 1. CONSOL Manufactured Aggregate Process Flow Scheme (Simplified). 


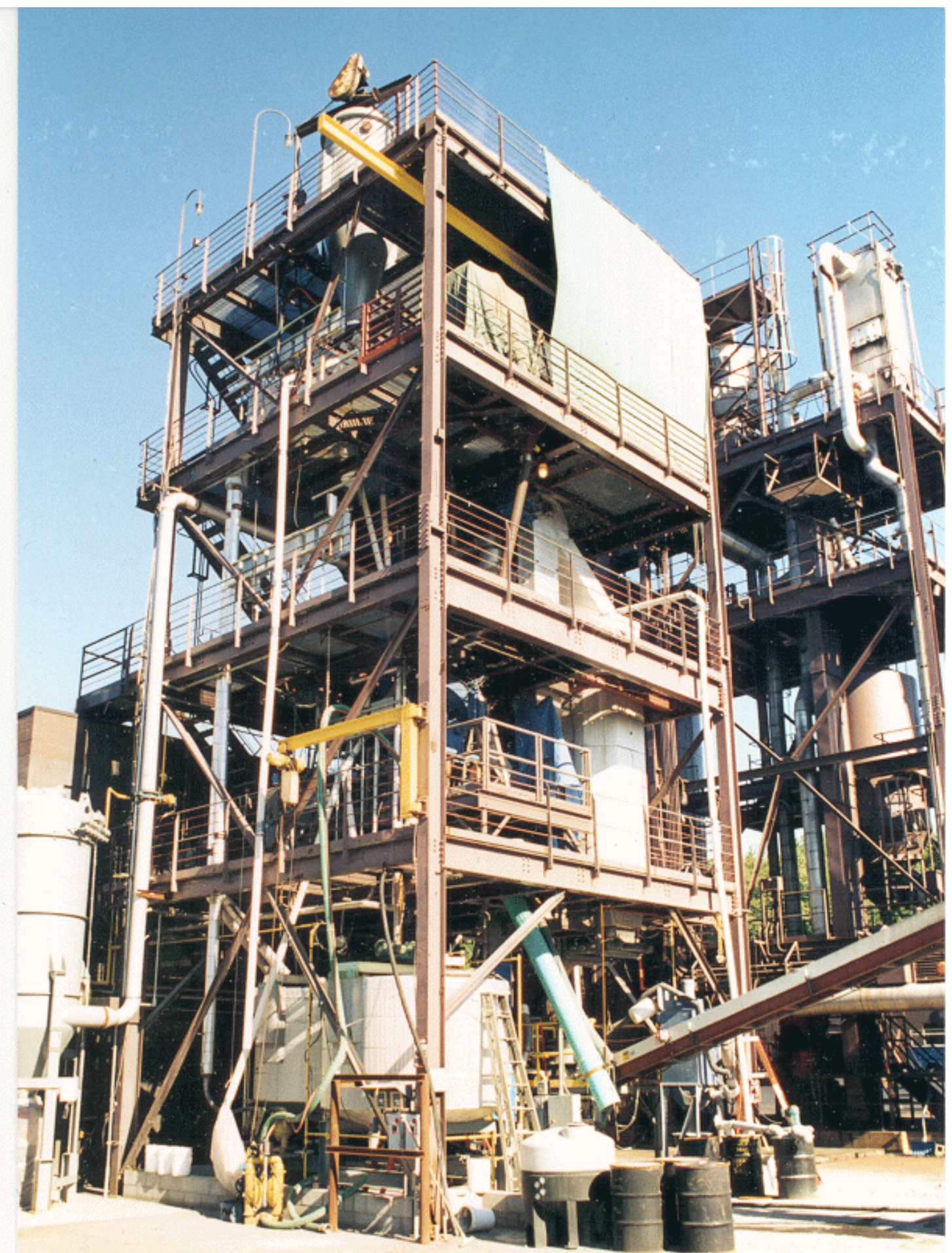

Figure 2. A Photograph of the Pilot Plant After Construction. 


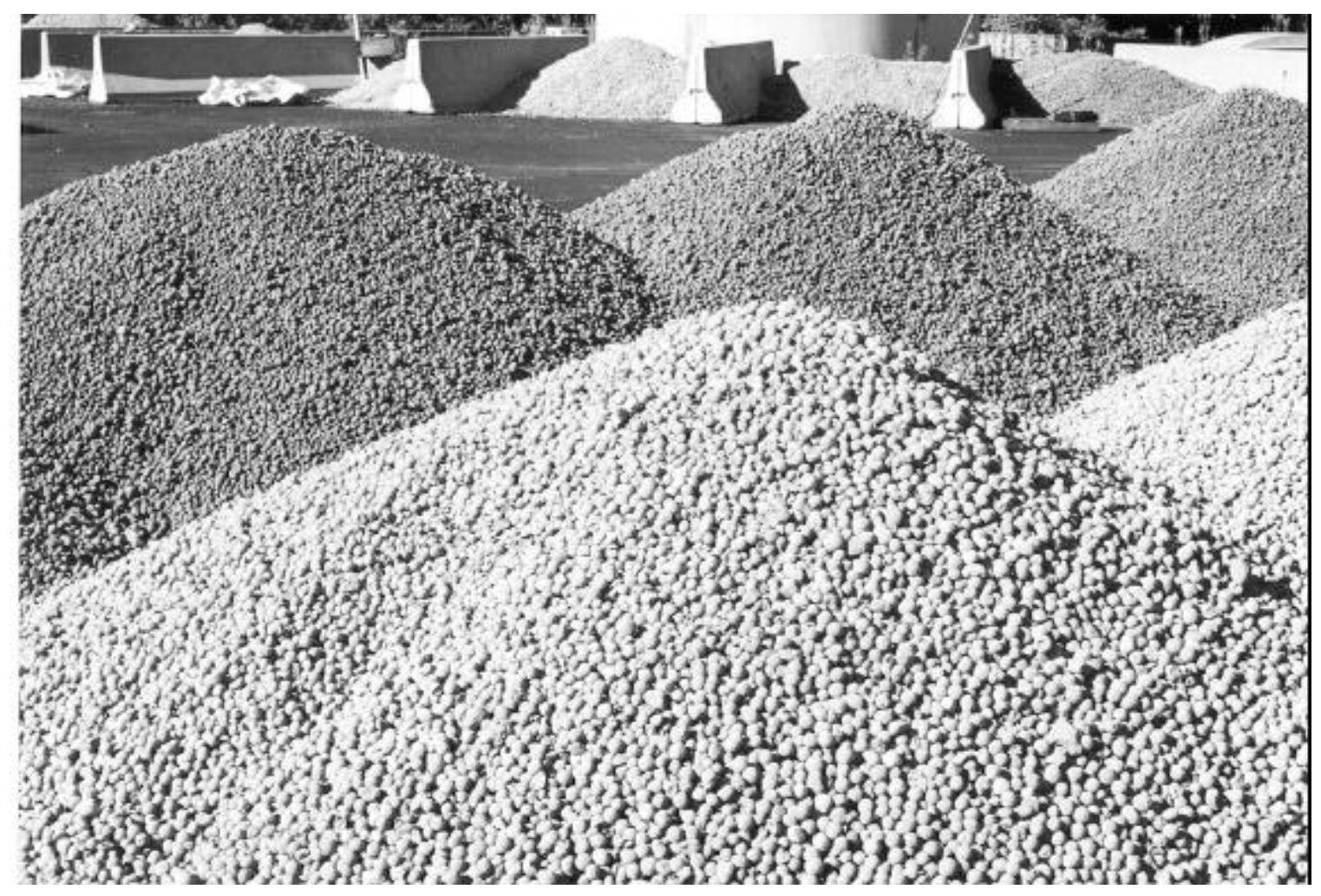

Figure 3. Manufactured Aggregates in Stockpile. 


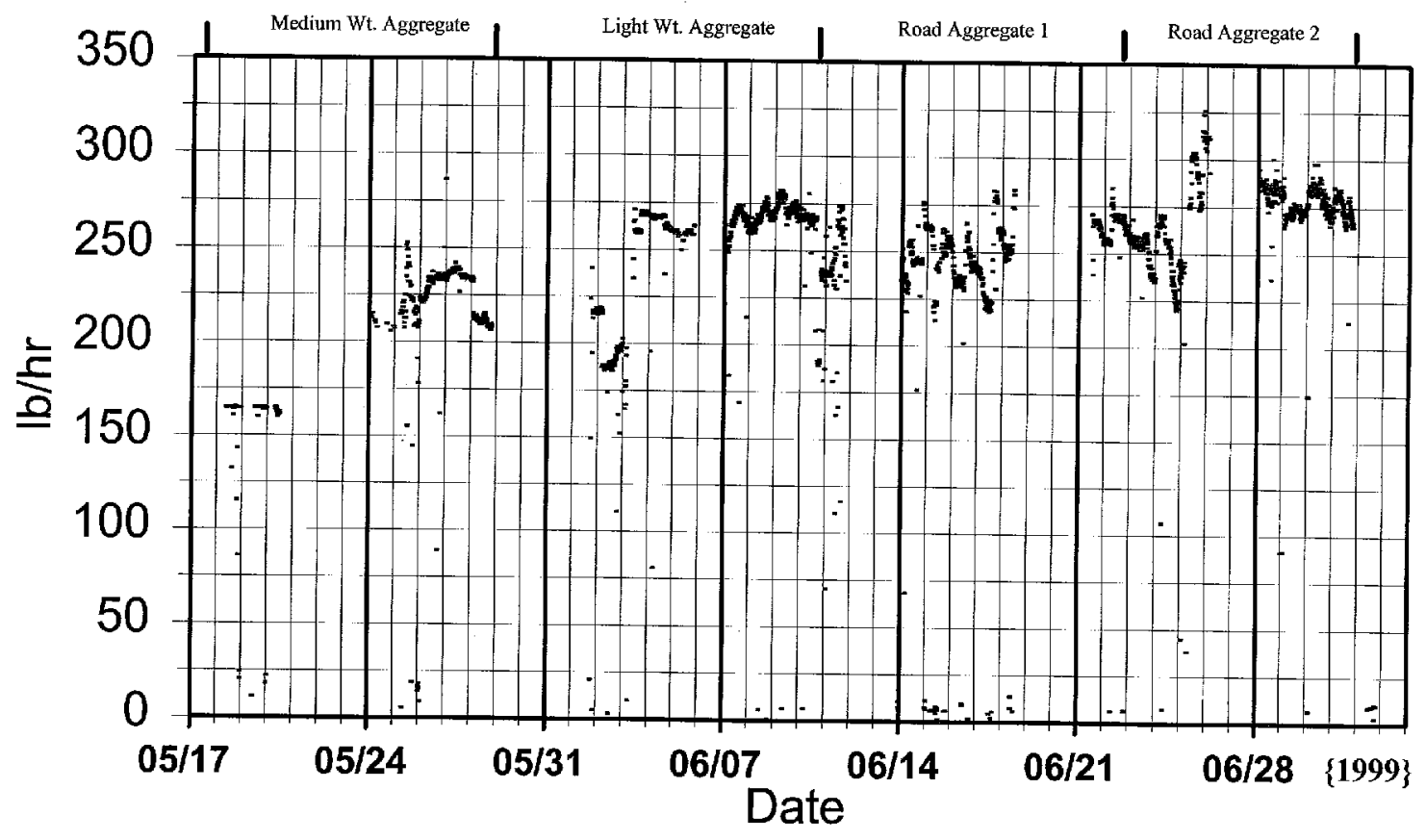

Figure 4. FGD Sludge to Mixer Rate.

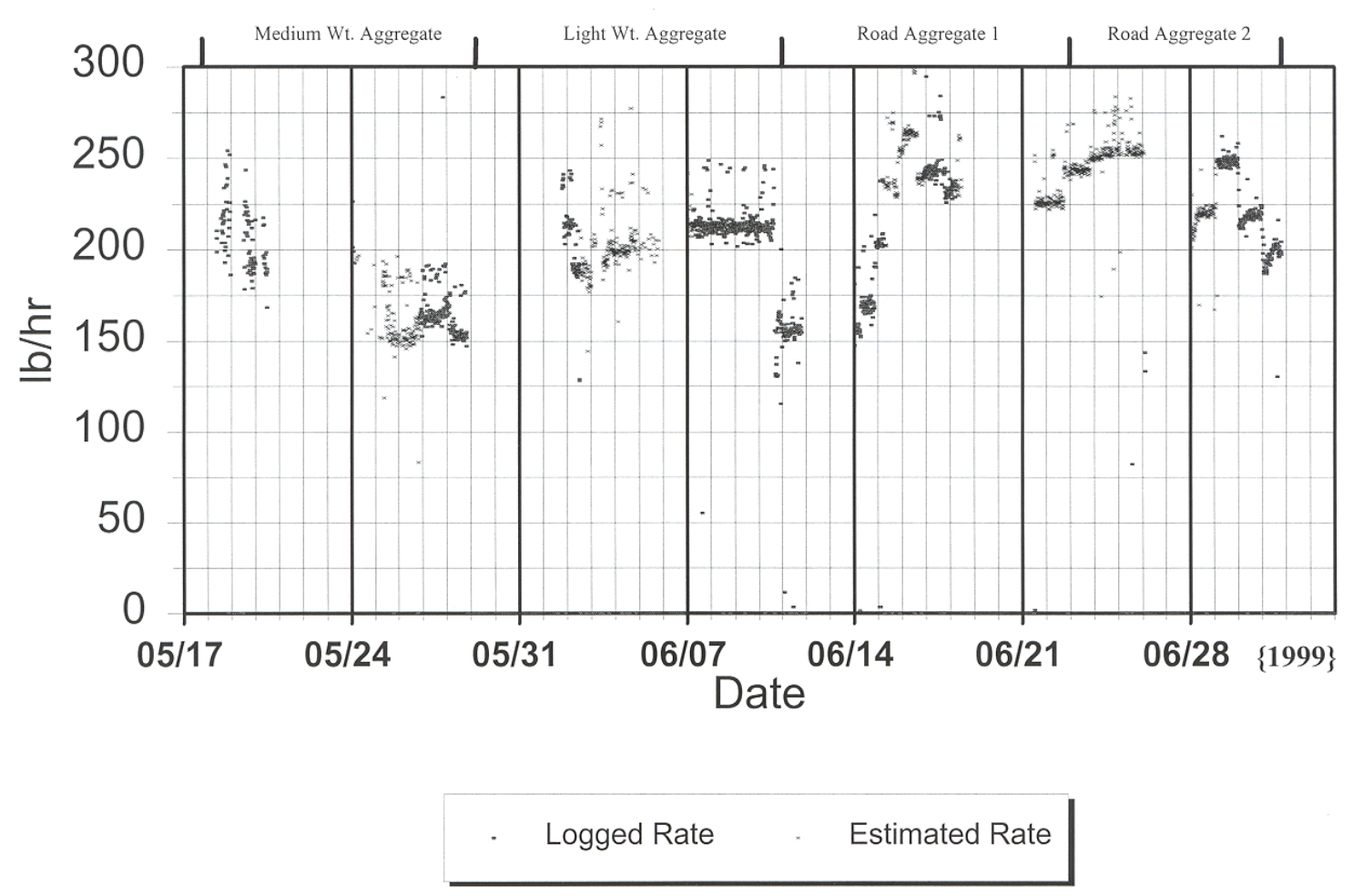

Figure 5. Fly Ash to Mixer Rate. 


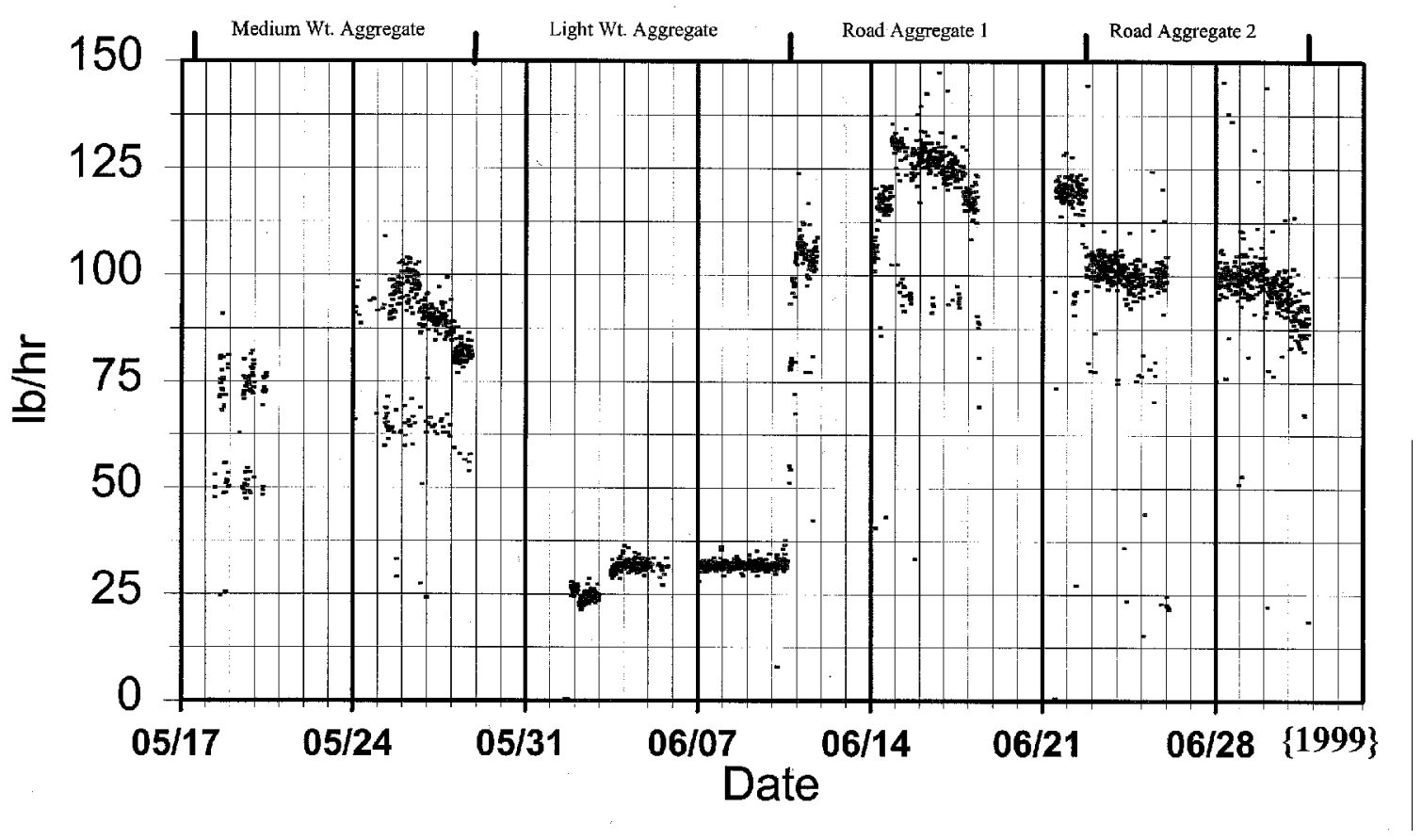

Figure 6. Other Components to Mixer Rate.

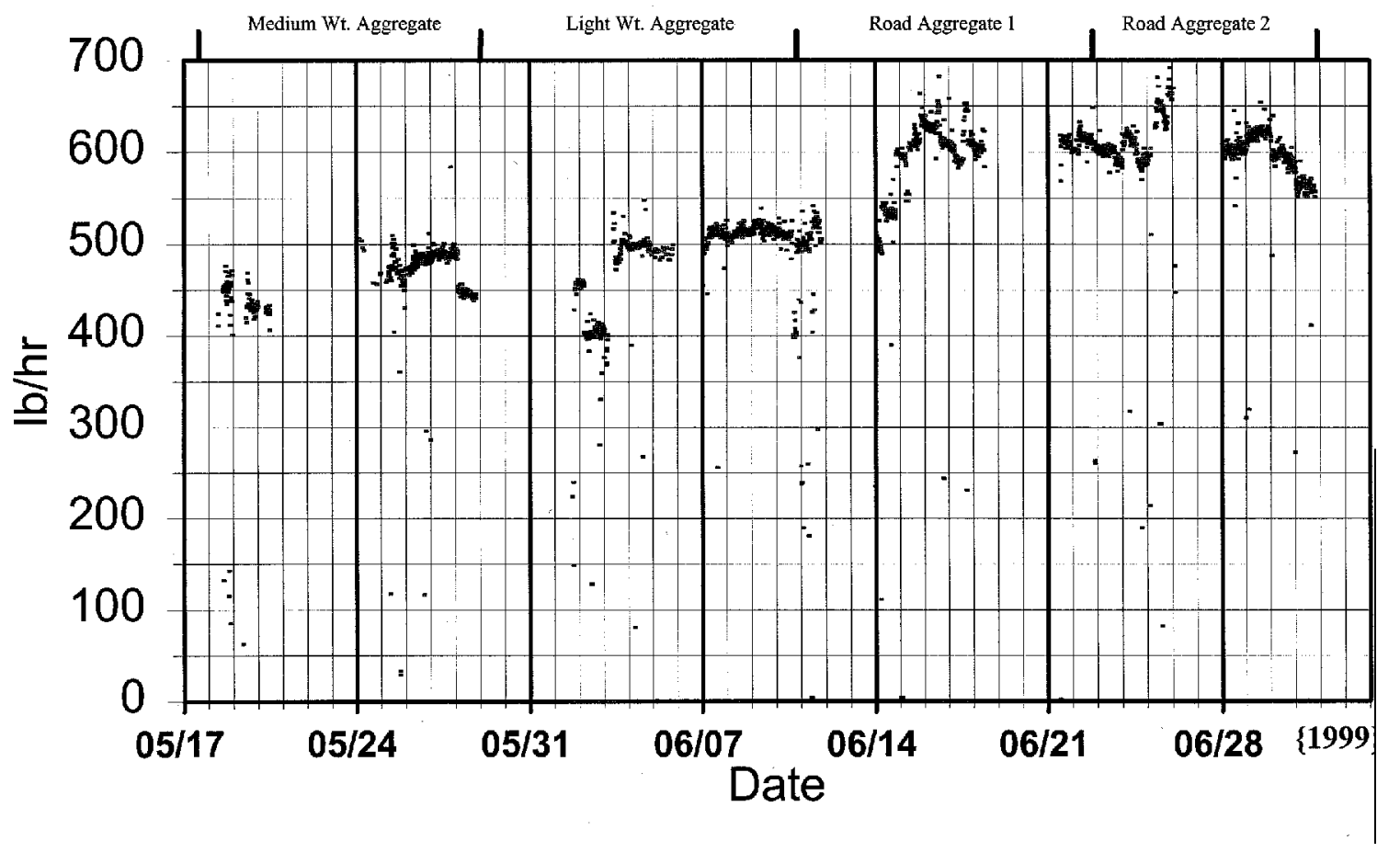

Figure 7. Green Aggregate Production Rate. 


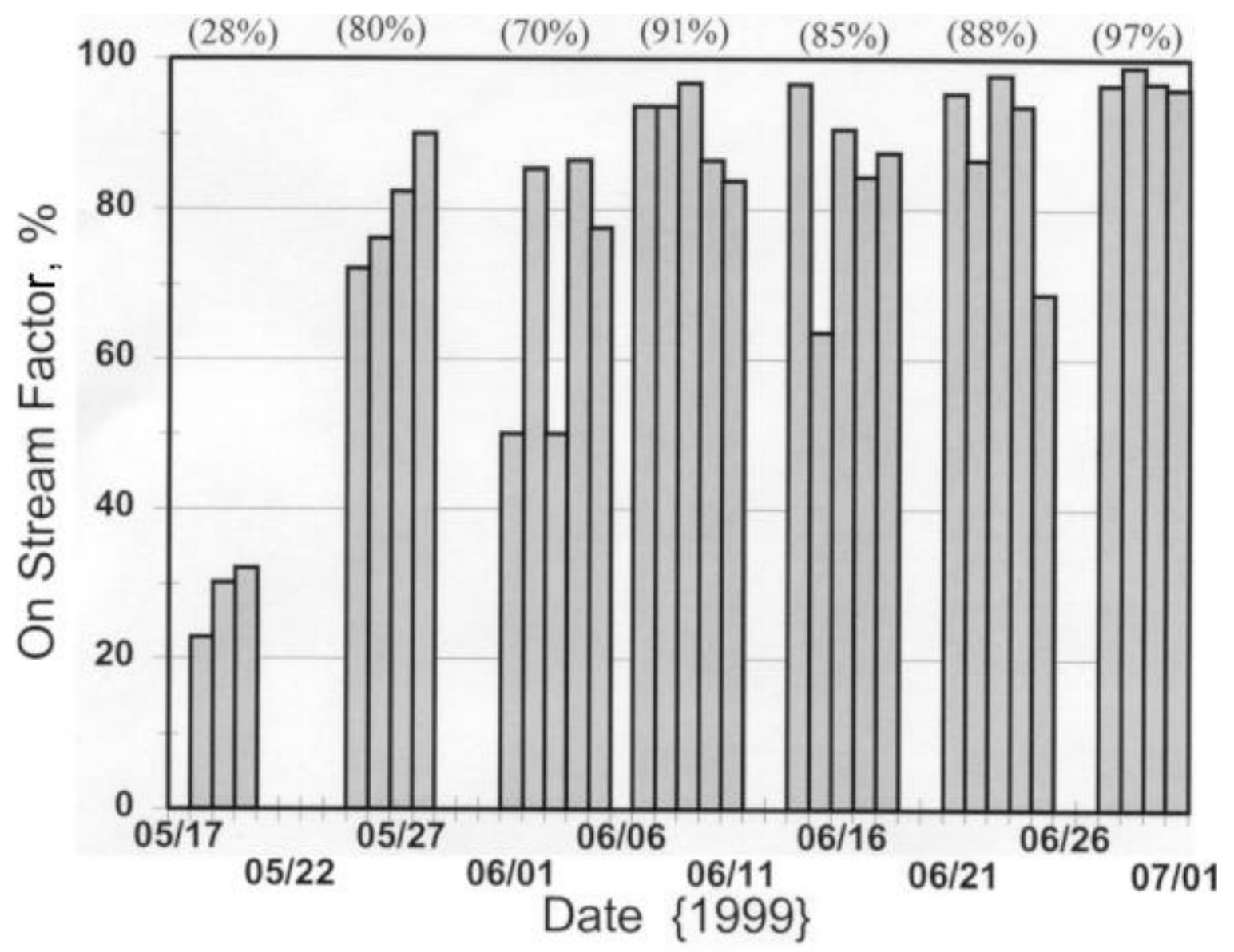

Average ()

Figure 8. On-Stream Operating Factor. 
Appendix A

OPERATIONS HISTORY

A1-1 


\title{
Appendix A
}

\section{MANUFACTURED AGGREGATE PILOT PLANT OPERATIONS HISTORY December 1998 to July 1999}

\author{
$12 / 28 / 98$
Received first truck load of fly ash $(7,220$ lbs.). Unloaded into the storage silo.

12/29/98 Checked out operation of the fly ash silo unloading equipment by transferring material to a tote bin.

1/26/99 To eliminate water leaks into the solids feeding systems, attached plastic sheeting around block valves on hoppers F-206 and F-204A/B, re-gasketed top inspection plates on feeders K-201and K-202A, installed plastic tents over the box enclosures that surround the feeders.

1/27/99 Began static calibration of the solids feeders. Worked with local manufacturer's representative.

2/1/99 Determined that the K-203 feeder scale range was too low because of increased solids density. This required that a factory technician replace a special balance spring.

2/2/-2/4/99 Calibrated solids feeders statically and dynamically.

2/9/99 Sludge mixer, M-102, speed controller blew out when the unit was powered up.

2/10/99 Checked out the operation of the sludge feed system by circulating water. Repaired piping leaks.

2/11/99 Checked out the operation of the sludge flow meter. The unit performance was erratic and unsuitable for flow rate control.

2/12/-2/15/99 Found a broken wire in the sludge flow meter. Repaired, but unit operation still unsatisfactory. Began working with manufacturer's representative to resolve the problems.

2/23/99 Began preliminary training of operators.

3/1/99 A manufacturer's representative arrived to modify the solids feeders. All feeder ranges were increased to better accommodate the use of higher density solids.

3/2/99 Modifications to the solids feeders were completed.

3/3/99 The sludge flow meter manufacturer's local representative reviewed the operation of the instrument and agreed that the unit was faulty. 
$3 / 8 / 99$

$3 / 16 / 99$

$3 / 17 / 99$

$3 / 19 / 99$

$3 / 23 / 99$

$3 / 24 / 99$

$3 / 29 / 99$

$3 / 31 / 99$

$4 / 7 / 99$

$4 / 8 / 99$

$4 / 11-4 / 12 / 99$

$4 / 13 / 99$

$4 / 15 / 99$
Ambient temperatures were too cold to allow operation of the solids feeders due to stiff gear drive grease.

Checked the calibration of several feeders. Partially filled the F-206 bin with fly ash in preparation for dynamic testing of the K-203 feeder. Also attempted to feed fly ash to F-204A/B bins. Wet material on the solids diversion valve between the L-305 screw conveyor and the F-204A/B bins fell into the bins. Found that the fly ash in F-206 bin was damp. Unloaded these bins and discarded the materials. Found that water was getting into the L-304 bucket elevator and the L-305 screw conveyor.

Sealed holes where water was entering L-304 bucket elevator and added a clean out port to the L-305 screw conveyor above the diverter valve to F-204A/B bins.

Began dynamic feed rate calibration of feeder K-203.

Completed the dynamic feed rate calibration of feeders K-202A and K-203 using fly ash material.

Dynamically calibrated feeder K-204.

Attempted to dynamically calibrate K-205 feeder. Had problems with the feed rate stability due to the lack of an enclosure around the feeder.

\section{Received the first load of FGD sludge (720 gallons).}

Calibrated the K-202A feeder on alternate material used for startup.

\section{Issued startup manual to operators.}

Checked out operation of the sludge metering pump. Obtained curve for new performance flow rate versus pump speed.

Checked out the performance of the sludge mass flow meter (loaner unit).

Operator training day. Transferred sludge from the F-101 storage tank to the F-102 feed tank.

Transferred fly ash to the F-206 bin.

Operated the front half of the plant for the first time and successfully produced a small quantity of green pellets.

Removed sludge metering pump suction strainer after strainer plugged.

Varied mixer speed and mix moisture content to adjust pellet properties. 
4/16/99 To improve product quality, reversed the last four mixer paddles to kick back solids and increase the mixing time per manufacturer's recommendations. Later reversed four more paddles. Mixing was better, but still needed improvement.

4/19/99 Reversed four more mixer paddles (12 total). This further improved the pellet uniformity, but particulate inclusions were still visible within the pellets.

4/20/99 Added three rods to the mixer blade tips in the F-101 sludge storage tank to improve the FGD sludge mixing. Visually the mixing appeared better, but, due to shaft vibration the mixer, could not be operated above 30-35 RPM. On May 4, the rods were removed when a large amount of settled solids was found in F-101.

4/21/99 Received the second load of FGD sludge (1476 gallons).

Received the second load of fly ash (11.4 tons)

4/23/99 Installed new sheaves on the L-201 mixer to increase the rotational speed.

4/26/99 Operated the L-201 mixer with six paddles reversed to kick back material rather than convey. The green pellets appeared to be more uniform without inclusions.

Mixer vibration was a problem. Repositioned mixer paddles so that only four were reversed. Vibration still was a problem.

Repositioned mixer paddles with no paddles reversed. Vibration was better controlled, but still a problem.

4/27/99 Cleaned mixer shell deposits and reset paddle clearances.

Initially, mixer appeared to over mix materials. Material had a paste-like consistency as opposed to fine damp particulate. To reduce the mixing duration, the sludge injection point was moved closer to the mixer discharge. Still obtained large agglomerated clumps of material from the mixer.

Cleaned the mixer and increased the mixing speed. Set green pellet production at $574 \mathrm{lb} / \mathrm{hr}$. Shutdown and cleaned out the mixer.

Adjusted solids feed rates to obtain $700 \mathrm{lb} / \mathrm{hr}$ green pellet production rate. Material became too dry, so the fly ash feed rate was decreased. Later, the mixer speed was further increased. The mix consistency improved greatly.

4/29/99 Checked out the pelletizer operation for different green pellet moisture levels.

4/30/99 Operator training day.

Installed new beveled paddles in the L-201 mixer to reduce vibration. 
Operator training day.

Changed position of the last four mixer paddles. Per the manufacturer's recommendations, the first two paddles were turned to convey towards the outlet. The last two were positioned to kick back.

Lost the M-102 FGD sludge mixer motor. Placed sludge pump on continuous circulation until motor could be replaced.

5/4/99 Operator training day.

The rods which had been welded to the blade tips of M-101 mixer to improve solids suspension were removed when a large amount of settled solids was found in F-101.

$5 / 5 / 99 \quad$ Took one shift to clean out $90 \%$ of the settled sludge solids in F-101.

5/6/99 Finished F-101 clean out.

Installed a temporary conveyor to feed expanded shale startup material into the B-300 curing vessel to establish a solids inventory.

Realigned belts on bucket elevators L-308 and L-207.

5/7/99 Loaded expanded shale into the curing vessel. Vessel two-thirds filled.

5/10/99 Completed filling the curing vessel with excess cured aggregate and crushed aggregate from the bench-scale unit.

5/11/99 Calibrated the K-205 feeder (static and dynamic) after feeder had been modified to improve operational reliability.

5/13/99 Operator training run. Took samples for curing.

5/14/99 Plant modification day. Completed numerous miscellaneous modifications and equipment changes including installation of a bag lifter for loading additives into tote bins and installation of a start-up dump line from the K-300 product belt feeder.

5/17/99 Completed installation of enclosure around K-205 feeder. Began bringing system on-line. Had a lot of operating problems, including plugging of the solids transfer point between the pelletizer and the curing vessel when the green pellet production rate was increased to $700 \mathrm{lb} / \mathrm{hr}$.

Fed green pellets for the first time to the B-300 curing vessel. Initiated medium weight aggregate production. 
5/18/99 The solids transfer point downstream of the pelletizer plugged a second time. Removed one third of the metal dam inside of the equipment to reduce the solids holdup in the unit.

The transfer point equipment from the pelletizer plugged a second time later in the day.

Ground out the remaining sections of the metal dam inside the transfer point equipment located downstream of the pelletizer. This was done to improve the solids flow through the equipment and to reduce the solids residence.

Experienced heavy rain storm late in day. A large amount of water ran into the funnel which feeds green pellets to the transfer point equipment downstream of the pelletizer. Had to shutdown to remove wet materials.

5/19/99 Unit was down at the beginning of the midnight shift. Cleaned wet material out of the solids transfer point equipment downstream of the pelletizer.

Cleared damp material from the line between the K-204 feeder and other equipment. Installed plastic sheeting around feeder discharge isolation socks on all feeders to prevent water entering the piping in the future.

Installed a line between the curing vessel vent port and the B-303 baghouse to improve humid air removal from the curing vessel.

5/20/99 The solid transfer point equipment downstream of the pelletizer plugged when an operator tapped on a feed line causing a material surge into the transfer point equipment. Shut down and cleaned out the equipment; also cleaned the discharge chute from the L-201 mixer.

Late in day production was cut back to reduce the fly ash consumption until a resupply truck could arrive. However, the $\mathrm{J}-103$ sludge metering pump operation could not be maintained. The system was shut down at 8 p.m. A plastic tie wrap was found in the pump suction. It was responsible for some of the pump operating problems.

$5 / 21 / 99 \quad$ Wet conditions were encountered in the equipment feeding solids to the transfer point downstream of the pelletizer and at the solids transfer point. Disassembled the equipment to clean and dry out the system. Determined that the rubber bellows connection between the solids transfer point equipment and the L207 bucket elevator needed to be disconnected when the unit is shut down. This prevented humid air from the curing vessel from backing into and condensing moisture at the transfer point. This became a standard operating practice for shutdowns.

Shutdown system for weekend.

5/24/99 Restarted the system. Lost the variable speed drive controller on the F-101 sludge tank. The controller shorted out. As a temporary fix, the motor was 
wired directly to the power source so that the mixer could be operated at full speed.

\section{Began operating the system in an integrated fashion with medium weight aggregate product going to the stockpile.}

During the last shift, the solids transfer point equipment downstream of the pelletizer plugged twice. Both times the unit was brought back on-line quickly by clearing the buildup of damp solids in the transfer point equipment. The problem was associated with the curing vessel vent line plugging. This line needed to be frequently cleared to prevent the backflow of moist air to the green pellet transfer point.

Solids transfer from the pelletizer plugged once during the first shift and once during the second shift.

During the third shift, the pelletizer angle was adjusted to determine the effect on aggregate ball size. Adjustments were $47^{\circ}$ to $50^{\circ}$ and later back to $49^{\circ}$.

To maintain sludge flow the $\mathrm{J}-103$ sludge metering pump had to be operated at higher speeds. The pump performance was deteriorating.

5/26/99 To eliminate pressurization of the K-205 feeder during refilling and to improve performance, the feeder hopper vent sock was eliminated. A baffled vent line made from PVC pipe and a small plastic bucket was used to replace the vent filter sock.

Unit shutdown for 8 minutes to clear jammed secondary plow in the pelletizer.

5/27/99 Unit shutdown for 10 minutes to adjust pelletizer plows.

The solids transfer point plugged four times during the day and evening shifts.

Received a load of FGD sludge.

The water seal flush was turned off on the $\mathrm{J}-103$ pump after the seal began to leak sludge.

5/28/99 The sludge pump seal began to leak excessively. To carry back the flow (approximately 20 gallons/hr.), a drain line was installed between the seal and the F-102 sludge feed tank.

As sludge pump performance deteriorated, the green pellet production was reduced.

The solids transfer point from the pelletizer plugged once. 
At 8 p.m. shutdown the unit for the weekend.

Inspected the L-201 mixer and found extensive wear on the12 paddles ahead of the outlet kick back paddles. In two weeks of operation the paddles had worn down and lost $3 / 4$ " to 1 " of metal.

5/31/99 System remained shutdown for holiday.

6/1/99 Replaced the 12 worn mixer paddles.

Installed three new plows in the pelletizer.

Installed a new electronics card in the sludge flow meter. The new card allowed the recording of the sludge density on the plant data logger.

Did not rebuild the $\mathrm{J}-103$ sludge pump. Parts (stator and rotor) had not arrived on site.

\section{At 8 p.m. started making green pellets. Initiated light weight aggregate production.}

6/2/99 During the first shift (midnight to 8 a.m.), the solids transfer point downstream of the pelletizer plugged three times.

6/3/99 During midnight shift, could not maintain green pellet size or sludge flow from the $\mathrm{J}-103$ pump. The pump was no longer operable.

Pump parts had been received, so pump was rebuilt during the day shift. System was back on-line at 10:00 a.m.

When unit re-started, the sludge injection point was moved from the last port nearest the L-201 mixer exit to the second from last port. Due to mixer vibration, the injection location was moved back to the last port after less than two hours of operation.

Received a load of FGD sludge.

6/4/99 Process was shut down for 35 minutes when the sludge flow was lost. Two plugs were found; one at the mixer inlet and one in the suction cavity of the metering pump.

Shut down the system for 5 minutes to clear the L-201 mixer discharge. Discharge area was two-thirds restricted.

To reduce mixer outlet chute plugging, set the last two paddles to kick back.

6/5/99 After the L-201 mixer and the exit chute plugged twice, the two paddles before the last paddle on the mixer shaft were adjusted to the sideways 
position. This was done to cause the conveyed solids to be thrown down the exit chute. Later reset the next to last paddle to the kick back position.

Damp solids plugged the discharge of the second screen deck in G-300. The screen was taken apart and cleaned. To prevent a future occurrence, the dust collection equipment around the screen was adjusted to improve removal of humid air from the screen. There were no other problems with the screen during the remainder of the testing.

6/6/99 System was not operated on Sunday. The curing vessel was recycled for 1.5 hours to ensure against inventory bridging.

6/7/99 Fly ash feeder controllers were adjusted to accommodate the low density of the Cheswick fly ash.

Received a truck load of FGD sludge.

6/8/99 The solids transfer point equipment downstream of the pelletizer plugged due to moist air backing into equipment when the vent line from the curing vessel plugged. Cleared both the plugged transfer point equipment and the curing vessel vent line.

6/9/99 To gain control of the green pellet ball size the pelletizer discharge was diverted to slops. During the diversion the transfer point equipment from the pelletizer was inspected. A 3"-4" thick buildup of damp material was found on the sides of the unit. This was removed.

6/10/99 The unit was shutdown for 10 minutes to clear the mixer when the ball size got too large. Wet solids and build-ups on the mixer shaft and paddles were removed. The large ball size may have been caused by temporary loss of one of the solids feeds to the mixer or possible solids hang up in a feed line.

The transfer point equipment downstream of the pelletizer plugged and had to be cleaned out. Later the equipment again began to plug but was cleared without shutting the process down.

Received a load of Hatfield fly ash. Began reducing the inventory of Cheswick fly ash in the system by dumping F-204A/B contents to bulk bags. Also dumped some component B material from F-206.

\section{Restarted unit and initiated road aggregate product production with additive $\mathbf{A} 1$ at alternate level.}

6/11/99 Lost flow from the Sludge pump. Shutdown to remove plastic tie wrap from pump.

Mixer plugged. Shutdown to clean out (15 minutes off line). 
The green pellet transfer point equipment downstream of the pelletizer plugged. Shutdown and cleaned.

Received load of sludge.

After system was shutdown for the weekend, the mixer was cleaned. Fourteen paddles were replaced due to wear and two were adjusted.

$6 / 14 / 99$

Installed a revised feeder chute to the pelletizer. The new chute had two sides made of rubber for easier cleaning.

Received load of sludge which was difficult to unload (took 3 hours).

Increased green pellet production rate from $532 \mathrm{lb} / \mathrm{hr}$ to $600 \mathrm{lb} / \mathrm{hr}$.

6/15/99 Went off line for 35 minutes when the green pellet transfer point equipment downstream of the pelletizer plugged. Disassembled and cleaned the equipment.

The chain drive on the L-207 bucket elevator that feeds the curing vessel required repair (worn out). Replaced the drive with a belt drive from L-308 bucket elevator.

The sludge feed line to the mixer plugged at the mixer due to low pump head pressure. Cleared and brought the system back on line.

The unit was shut down for 10 minutes to allow cleaning of the green pellet transfer point equipment located downstream of the pelletizer.

6/16/99 Received load of sludge. Took 2.5 hours to unload.

Unit was down for $1 / 2$ hour to rod out the sludge line at the mixer (discharge was crusted over).

Shutdown for $1 / 2$ hour to clean the green pellet transfer point equipment.

6/17/99 Modified the sludge feed line to the mixer. Repositioned the discharge to $1 / 4$ " from the paddle tips. Cleaned the mixer and replaced two paddles.

6/18/99 Received truck load of sludge.

Lost ability to make green pellets. Shut down the unit. Found that sludge feed to the mixer was crusted over, and found a plastic tie wrap in the sludge pump. Cleaned out the mixer and sludge pump.

Had to shut down again and clean out the mixer when it became impossible to make green pellets. Cleaned out mixer and flushed sludge lines. The sludge pump needs to be rebuilt to correct the operating problems. To reduce the residence time of the green pellets in the transfer point equipment 
located downstream of the pelletizer, an internal diversion plate was installed.

Inspected the L-207 bucket elevator and found nine damaged buckets which needed to be straightened or replaced. Unit was operable so repairs were scheduled for a normal shutdown period.

Unit shutdown for weekend.

6/21/99 Repaired sludge pump by replacing stator.

Restarted system.

$6 / 22 / 99$

$6 / 23 / 99$

$6 / 24 / 99$

$6 / 25 / 99$

$6 / 26 / 99$

$6 / 28 / 99$

\section{Changed additive from A-1 to A-2. Initiated production of alternate road} aggregate mix.

Shut down unit for 10 minutes to clear the sludge line to the mixer.

Received a truck load of sludge.

Had a problem with maintaining pellet ball size due to changing moisture concentration of feed sludge after sludge was transferred from receiving tank, F-101, to the feed tank, F-102.

Replaced the 3/8" dia. plastic tubing sludge feed line between the pump and the mixer with a $1 / 2$ " dia. rubber hose to reduce the sludge pump discharge pressure. The pressure drop decreased 5-6 psi.

The outboard process side seal on the sludge pump began to leak excessively.

The green pellet transfer point equipment located downstream of the pelletizer plugged and had to be cleaned.

Attempted to operate the fluid bed heater as a vibrating conveyor. However, materials sifted backwards through the porous metal air flow distribution screen. Decided to by-pass the heater totally.

Received a truck load of sludge.

Extended unit operation for one additional shift to make up for lost production earlier in the week. Then shutdown for weekend.

Replaced 16 mixer paddles with new hard faced paddles.

Shutdown unit for 5 minutes when the green pellet transfer point equipment located downstream of the pelletizer began to plug. Cleared the equipment through the top access port. 
6/29/99 Received truck load of sludge.

6/30/99 The green pellet transfer point equipment located downstream of the pelletizer plugged and had to be cleaned out.

7/1/99 Shut down unit for 10 minutes to clear pelletizer discharge solids feed funnel.

The solids transfer point from the pelletizer plugged.

\section{Ended the test program at 20:00 hours after product inventory target was achieved.}

Inspection of the mixer showed that the paddles had worn down 3/8" to $1 / 2$ " in four days. For this application there is a need for better hard facing materials.

7/7/99 Began emptying the curing vessel to recover additional product and allow for vessel inspection.

7/8/99 Completed the emptying of the curing vessel.

7/15/99 Inspected the curing vessel using a video camera. The vessel appeared to be in good condition with no evidence of erosion or corrosion. Only minor amounts of deposit materials (estimated to be less than $1.2 \%$ of the vessel inventory) were found in some localized areas. 